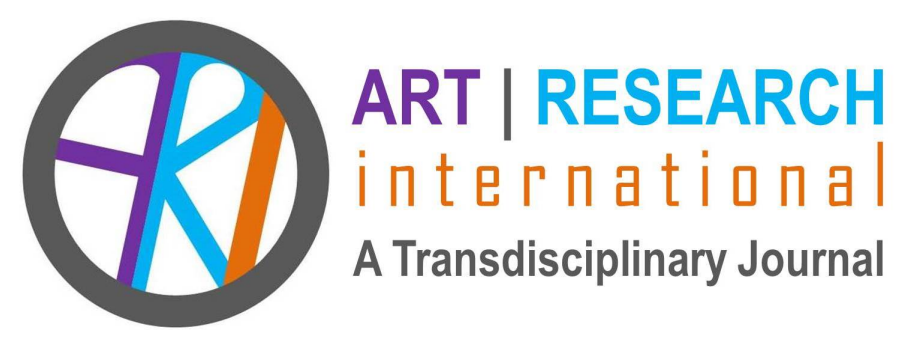

\title{
THE ART OF SILENCE: RESEARCHING THE ROLE OF SILENCE IN NATURE BASED EXPRESSIVE ARTS
}

\author{
Alexandra Tegart \\ European Graduate School \\ alexhtegart@gmail.com
}

\begin{abstract}
Alexandra Tegart received her MA in expressive arts therapy from the European Graduate School, Switzerland. She is currently a counsellor based in Vancouver, B.C., Canada. She is continually inspired and motivated by the power of the arts to heal and humbled again and again by the resilience of the human heart.
\end{abstract}

Abstract: This paper journeys into the aesthetics of silence in nature-based expressive arts practice and research. Explored is how nature-based expressive arts (EXA) therapy can help cultivate an embodied sense of silence to nourish and support frontline mental health workers in the Vancouver Downtown Eastside, easing the stresses of assisting a population in the midst of an opioid and overdose crisis. The transformational effects of EXA are discussed as they relate to a short series of workshops with frontline mental health workers from Vancouver's PHS Community Services Society. We collectively experienced how the phenomenon of silence can help provide a rich resource to care providers and, in turn, inform the nature of our research in vulnerable communities.

Keywords: aesthetics of silence, deep ecology, poetic ecology, opioid crisis, ecoaesthetics, expressive arts 


\section{Traversing the Schema}

This work arose directly from personal experience as a frontline mental health worker in Vancouver's Downtown Eastside (DTES), struggling to find work life balance and healing. Through my attempts to find nourishment and solace during trying times on the job, I encountered the sanity of silence in nature and the transformational effects of shaping and becoming through art making and my training as an expressive arts practitioner. This research is an extension of that unearthing.

In the sections herein, I outline the nature of Vancouver, British Columbia's opioid and overdose crisis, and some of the complexifying features that include poverty, a legacy of housing shortages, and the emergence of dangerous new synthetic drugs. These are all exacerbated by a vastly inadequate response by the public health and social services systems.

This research looks at how silence - the thread that binds and leaves space for pauses, reflection and impulses to naturally arise - can become an embodied response that nourishes and brings depth to the practice of expressive arts therapy. Further, its practise can renew our sense of connection to self, community and the people we work with and for.

\section{The Context}

"silence - the thread that binds and leaves space for pauses, reflection and impulses to naturally arise can become an embodied response that nourishes and brings depth to the practice of expressive arts

During the 1970s to 1980s, therapy." Vancouver, BC experienced a steady loss of Single Room Occupancies (SROs) providing affordable housing for those on income assistance. Between 1978 and 1982, the number of units were reduced by 1,987 and by 1981, ninety per cent of these units were occupied (Campbell, Boyd, \& Culbert, 2009, pp. 42-43). Access to affordable housing in Vancouver is still a problem. According to a City Council report, in 2015 Vancouver had a 0.5 percent vacancy rate (City of Vancouver, 2015). Among units built from 2014 until February 2016, for every eight charging rents above the welfare rate, only one was built to be made available at the welfare rate. In total, there are 205 units that low-income people can afford in the city, and 1,663 they can't (Carnegie Community Action Project, as cited in Seccia, 2017). 
Vancouver's hosting of the Expo 1986 World Fair marked a change in the landscape of the DTES. It brought tourism and economic revenue, but also a shift in the community's drug culture. The provincial government drove to maximize tourist units while not disturbing wealthy foreign visitors' sensibilities with potentially grim images of Vancouver's inner-city poverty. Foreign drug dealers brought in higher quality cocaine that users began injecting and the result was that the rates of overdoses significantly increased. In the past, the purity of cocaine sold at the street level was between fifty to seventy-five per cent. After Expo 86, cocaine was at a ninety percent purity level, which resulted in six fatal overdoses in 1986 (Campbell et al., 2009, pp. 42-43).

By the 1990s, the province of British Columbia was suffering from an overdose crisis. At its peak, in 1998, there were 400 overdose-related deaths: half of which took place in Vancouver. The BC government was mobilized by local activists to support harm reduction as a strategy that mitigates the risks of harm caused by addiction, while not requiring cessation as a condition of engagement (Lupick, 2017, p. 374).

\section{Epidemic Proportions}

Now in 2019, the city of Vancouver, like many other places in Canada, is in the grips of an opioid crisis. According to the Coroner's Service of BC (2019), the area covered by the Vancouver Coastal Health Authority has experienced its highest rate of illicit drug overdose deaths: 36.5 per 100,000 in 2018. From the same report, death rates from overdoses in $\mathrm{BC}$ are listed as having been at 211 in 2010, before rising sharply to 1514 in 2018. Vancouver's overdoses are recorded by population rates to be presently at 56.2 per 100,000 ; nearly $80.1 \%$ of those who have died of overdose had fentanyl in their systems.

Fentanyl, a synthetic opioid some 50 times stronger than heroin, has come to public attention these past few years as the cause of the epidemic frequency of North American drug overdoses. In 2016, Dr. Mark Tyndall, then executive medical director for BC's Centre for Disease Control, stressed the importance of supporting and funding proven treatments including increased access to Naloxone (a medication used to block the effects of opioids, especially during overdose); better substitution therapies such as injecting morphine under supervision; and increased capacity and hours for supervised injection sites such as InSite in the Downtown Eastside (Brend, 2016). At the time of the study, the research participants and I were working as support staff and "first responders" at these sites. 
The situation for residents of the Downtown Eastside is exacerbated by the increased levels of stress being experienced by front line mental health workers who care for them. Logically and relationally, they are "first responders" to crises before the official first responders are summoned to critical events requiring emergency team responses during high stakes circumstances. Occupying positions offered by agencies under contract to different government and health authorities, front line mental health workers are often minimally paid and receive inferior benefits than those enjoyed by both government employees holding comparable positions and those professionally recognized as first responders.

During emergencies, front line mental health workers administer certain health care interventions, such as intubating an overdosing client and administering Narcan (Naloxone). The life of their clients literally in their hands, front line mental health workers exist within complex relationships alongside the official first responders (police, firefighters, and emergency medical technicians) who also share the trauma of such situations. These are professional, yet highly personal relationships that have been forged between staff members and clients.

Supports for front line community health workers from community-based organizations have continued to typically fall short. In 2017, the Central City Foundation, an organization that supports Vancouver's inner-city nonprofits and organizations, released a report titled, "On the Frontlines of the Opioid Crisis," which included in-depth interviews with frontline workers, shelter managers, health workers, program managers, directors of non-profit organizations, and social service agencies.

Common consensus among the organizations was that the opioid crisis was having a severe impact on their operations, their staff and their clients: and all are feeling significant strain due to the ongoing crisis. More than 71 percent of organizations say that the opioid crisis is having a direct impact on their staff and their work with people in the inner city. Another 29 percent say the impact of the crisis has been indirect, but still highly significant (Central City Foundation, 2017). Front line mental health workers not only serve their clientele as they navigate the vagaries of urban settlement, but also they personally endure the challenges increasingly common to metropolitan life.

Further, the housing crisis in Vancouver no longer affects just the economically and socially marginalized, but also any resident and prospective tenant impacted by gentrification and rising property costs. 


\section{Silentium Naturae}

At times, when faced with the enormity of the situation, the inclination of the EXA therapist is to move towards feeling overwhelmed and helpless. There are no words. Silence. And the stillness in death is both silent and full of screams. The screams of people, sirens, the jolts of trolley lines, and tempos that mark both the existence of the city's life and its casualties. The EXA therapist is left to her work one hour at a time, stillness wrapped in hypervigilance to the moment she will need to spring into action. The toll on the bodies of the worker, client, and the city itself leave scars.

Nature has the distinct ability to shake my senses out of the dullness that can ensue after an overwhelming week at work. As Knill (2005) explains, we are woken from the spell of dullness, an anaesthesia to protect ourselves from the harshness of seemingly "abusive realities" we encounter when we are touched by the beauty of an artistic act or an artwork. Beauty in this context is not measured by an "objective ideal." Here, beauty is a response that has bodily origin, a response that is both profound and soul stirring, and that takes our breath away. This is an aesthetic intervention that can only take place when enough space in the work is provided to activate the senses to the point whereby established trust and confidence can encourage a sensory responsiveness (Knill, 2005, pp.136-138).

\section{Urban Spaces, Recasting Nature}

As Knill (2005) explains, we have a special challenge in confronting the anaesthetizing mechanism in the world of today: "Could it be that genuine beauty has absented itself from our daily life to such an extent that we have to anaesthetize ourselves in order to protect ourselves from abusive realities?" (p. 138).

This research explores silence in the context of nature-based expressive arts practice and looks at ways in which the aesthetics of silence can help inform the therapeutic process. It considers how this rich and nuanced phenomenon of silence can both nourish and shake the senses alive, out of the stupor of emotional overwhelm and anaesthesia. It explores the different ways of being with silence in nature through a process of poiesis: "knowing by making" or being made by knowing (S. K. Levine., 2005, p. 32). This is significant for me as an EXA therapist working in Vancouver, British Columbia, and specifically one providing supports to front line workers serving residents of its Downtown Eastside. 
An expressive arts (EXA) therapist constantly refines the dance between knowing when to respond with silence and when to respond with words and form. Sometimes the simple offering of space, a place for the client to be and be seen, is all that is needed. Therein, therapeutic silence is not simply the absence of humans conversing with each other, but is a complex relational assemblage of humans with animals, green spaces, oceans and the organic and inorganic spaces that they occupy. Our silence, in some ways, may attune us to what these other parts of worldly existence are communicating.

Silence takes form in therapeutic sessions with clients. When an EXA therapist starts to judge, silence settles those jumpy thoughts and naturally gives more space to the client and that which emerges. Silence has tempo, demands space, deeply engages, and sometimes frustrates (Cage, 1961). Moving out of the way and allowing the process to be "led by the power of the thing" becomes the phenomenological approach of intermodal EXA therapy (Knill, 2003, p. 23).

Vancouver's Downtown Eastside features relationalities of acoustic intensities: flashing lights, dissonance between buildings empty of people and people propped up around them. A 'silent dance' of rubbing shoulders, of chemical interactions, and of crystallization produce passions (Deleuze, 1988, p.77).

\section{The Literature}

\section{Act of Poiesis}

Paolo Knill (2005), one of the founders of EXA, theorizes a process of therapeutic decentering. He envisions the EXA therapist as a change agent; and through an engagement with intermodal forms of artistic play, a client is able to engage both the imagination and the bodily sensations to offer a different experience of the world. A participant sets the present issue to the side in order to mobilize a different future. The very act of walking into a forest and re-affirming a human's shared citizenship with the lifeworld on earthy space may be blown open with smells, sounds, textures, shapes and taste. An attunement to one's agency amongst other living things requires a refocusing or a reassembly of a human body with all that shares a common agency. A crooked creaking tree, a moist riverbed, or drops of dew on a leaf tip include us in a reality that we are increasingly unfamiliar with.

In the context of EXA practice and theory, poetics (or poiesis) is understood as the artistic form emerging out of chaos, which seeks its own shape. Poiesis happens through the experience of surrendering and letting-be (S. K. Levine., 2005). The 
therapeutic effect comes from the ability of the therapist to stay with the nothingness, without imposing a new structure (S. K. Levine, 2005).

\section{Re-framing Trauma}

In the book Trauma and Recovery, researcher Judith Herman (1992) writes that "trauma is contagious" (p.140). When the therapist is witness to a disaster or atrocity inflicted on another, they can, to a lesser degree, experience the same terror, rage, and despair as the client in a phenomenon termed vicarious trauma. Herman (1992) explains that the therapist is repeatedly exposed to stories of human cruelty that can "challenge a therapist's basic faith" (p. 141). In such cases the practitioner who bears witness may have a heightened sense of vulnerability and may become more fearful and distrustful, even in personal relationships.

Another trauma expert and psychologist, Peter Levine (2010) explains in his book, In an Unspoken Voice: How the Body Releases Trauma and Restores Goodness, that as social creatures, we make our deepest connections through empathy as we resonate with sensations and emotions of others. The way we do this is "primarily nonverbal" (p. 42). P. Levine avers that, as practitioners, if we are not able to attune and track our own bodily sensations and emotions, it becomes difficult to help clients track their sensations and thus navigate difficult traumatic sensations. He also points out that in learning to track one's own sensations, practitioners can avoid "absorbing the fear, rage and helplessness of the client" (p. 42).

P. Levine (2010) states that if practitioners feel they must block themselves from a client's disturbing emotions, they are also distancing themselves from the client and ultimately abandoning them. This self-protective stance, he writes, greatly increases the likelihood of exposure to "secondary or vicarious traumatization and burnout" (p. 42). Healing trauma must engage the feeling and "knowing" body of both client and practitioner, claims the analyst Leston Havens: "Perhaps the most striking evidence of successful empathy is the occurrence in our bodies of sensations that the patient has described in his or hers" (1979, cited in P. Levine, 2010, p. 42-43).

Atkins and Snyder (2017) write of Hernandez, Gangsei and Engstrom's (2007) concept of vicarious resilience that, "when we hear the stories of a client's strength and growth through adversity, [we experience] our own abilities to navigate change, loss and threat" (cited in Atkins \& Snyder, 2017, p. 121). Vicarious trauma and resilience can extend to the eco-sphere. When we are exposed to the threat of species loss and the destruction of the natural world, we may experience "vicarious eco-trauma" (p. 121). 
However, when we experience the triumph of a repopulation of a near-extinct species, for example, we can also experience "vicarious eco-resilience" (Atkins \& Snyder, 2017, p. 121).

In the article, "Resisting Burnout with Justice-Doing" activist, Vikki Reynolds (2011) explains that the problem of "burnout" is rooted in the world where there is lack of justice. Reynolds asserts that burnout is not simply a condition within the mind of the individual worker and that it is not the client who created it; in the broadest sense, selfcare is not enough to offset systemic issues of poverty and violence (pp. 28-29).

\section{Poetic Ecology}

In the article, "Nature as a Work of Art: Towards a Poetic Ecology" S. K. Levine (2012) explores the notion of a "poetic ecology," one in which nature can be considered a work of art. Nature does not mean that which is "wild and untouched, but that which has been shaped in a way that respects its otherness" (p. 193). S. K. Levine (2012) explains that in our human finitude, the earth will always be beyond our power, so the proper attitude towards it is awe. Beauty, in the context of a poetic ecology, emerges from the awe with which we see and experience the world and beings that live in it. Beauty is what touches us through the senses and takes our breath away, the generator of an aesthetic response. As explained above, we are sensing beings. Aisthesis is a Greek word meaning "pertaining to the senses." Aesthetics, therefore, refers to the ways in which we sense the world. Poiesis is the way we shape the world (and it shapes us) according to our senses. We therefore can say that "we have an aesthetic responsibility to the world" (p. 192). As shaping animals, human beings shape the world around them (including the natural world). The arts as a mode of showing can reveal to us the ways in which we have made the world ugly and can also point towards what is possible (S. K. Levine, 2012, pp.191-192).

Per Espen Stoknes (2015), a Norwegian expressive art therapist and ecophilosopher, widened the scope of poiesis to also include the more than human world as he discussed the poiesis of the air. In this example of "ecopoiesis," he explains how the living air is actively involved in being and becoming, and how our psyche and life-breath is participatory. Stoknes challenges the Western-centric notion that humans are separate from the earth, air, and oceans, and asks us to consider where the self ends. The air we breathe along with oxygen in our lungs and blood, point to the fact that the air is not just "out there." We share the air that we breathe with the trees, animals and fish in the sea and what we think of as the separate self is actually a web of relationship (Stoknes, 2015, cited in Atkins \& Snyder, 2017, p. 89). 
In Nature-Based EXA Therapy: Integrating the Arts and Ecotherapy, Atkins and Snyder (2017) outline three foundational concepts in the practice of nature-based EXA ,therapy: a worldview of interrelationship, ecological presence, ecopoiesis, and the arts in service to life. The worldview of interrelationship describes the belief that the world consists of layers within layers of interrelationships and that we are a "communion of subjects rather than a collection of objects" (Berry, 1988, cited in Atkins \& Snyder, 2017 , p.1 17); this communion is intimate and sacred. An ecological presence takes into account the quality of presence as being both a personal quality of attention and as a relational process. Ecological presence brings this quality of attention into our relationship with the earth, of being in the world with sensorial awareness and the imagination. Ecopoiesis sees the creative process of humans as embedded within the ongoing creative process of the living earth (Atkins \& Snyder, 2017, p. 117-119).

The silent self-listening is the beginning of the pathless path of EXA therapy. This notion of wandering is a way of thinking and being. It rejects the theory of truth as corresponding to what already is present in front of you. In EXA, it is in this wandering, this letting go of goal-directed behaviour, that client and practitioner decenter into an "alternate world experience," using the arts and disciplines of the imagination, to uncover new possibilities that were once covered up by over-focussing on the problem of a situation (S. K. Levine, 2015, p. 19). As Knill (2005) explains, in EXA the "gift of the alternative world experience is a restoration ritual [...] time out into the realm of the imagination in order to find new ways of handling one's concerns" (p. 164).

In Presence and Process in EXA Work author Atkins (in Eberhart, Atkins \& Knill, 2014) explains the importance of daily rituals and practices to support practitioners in staying grounded and focused on the present moment: with the client and for self-care. A daily practice is understood to be one that is engaged more days than not and that allows the individual to have gentleness with themselves. These can include walks in nature, meditation and mindfulness practices and arts-based practices. These practices, or simply taking a "moment of silence and self-awareness," can all be a practice of presence (Eberhart et al., 2014, p. 80).

\section{Deep Ecology}

Arne Naess, credited with coining the term "deep ecology" (1973), brought forth a way of recognizing the equally intrinsic value of all biota, as well as one's interconnectedness with the lifeworld by way of direct experience of non-human nature (cited in Nelson, 2008, p. 206). Deep ecology theorists, such as Naess, felt that we are largely in a "crisis of perception" (Kellen-Taylor, 1998, p. 306-307). 
Deep ecology has two founding principles: biotic egalitarianism and metaphysical holism. Biotic egalitarianism asserts that biota have equal intrinsic value. Every animal and plant life-form is regarded as important. Metaphysical holism is the idea that we can make no firm ontological divide in reality between the human and non-human realms (Nelson, 2008, p. 207-208).

Despite criticisms, deep ecology has nonetheless had a dramatic impact on ecology, psychology and therapeutic practice. Its recognition of the intrinsic value of all living beings has moved us away from the experience of alienation and fragmentation. It moves us towards what Naess (1995) called an "ecological self," which involves a "repopulation of our imagination and memories with direct experiences of nature" (cited in Kellen-Taylor, 1998, p. 308).

\section{Methodology}

Low skill/high sensitivity

Working with what we have

My own ability to be present Is one of my greatest resources

From that place of presence

Comes trust

In myself, in the client, in the work

How this work can be so simple

Yet so profound.

Untitled by Alex Tegart (2017)

My journeys into nature, spending time in silence in conjunction with training in expressive arts therapy, were my salvation. This made me curious about whether a specific combination of silence and nature-based expressive arts practices could help others working under similar high-stress conditions.

Expressive arts-based research draws from a broad set of research traditions. These groups may well be considered a case study, collaborative research or participatory action research. Arts-based research finds its home naturally in the work of expressive arts. It is a form of qualitative research that employs the procedures and 
principles of the arts, with the presence of aesthetic qualities embedded in both the inquiry process and research text (Barone \& Eisner, 2012, p. 29).

In this case, research is participatory, and data is co-generated. The heuristic stylings of Moustakas is embraced, starting with the identification of a question that is deeply felt by the researcher and participants, one that may be considered urgent and not-to-be ignored (Moustakas,1990, as cited in Kenny, 2012, p. 6-7). A foundational EXA concept of low skill/high sensitivity, where sensitivity toward the materials we work with is prioritized over virtuosity of manual skills, were a guiding element at the roots of the nature-based workshops in this research (Knill, 2005, p. 98).

\section{Methods Sensoriums: Aesthetics of Silence}

The aesthetic of silence was an important guiding theme while planning and facilitating the workshops. I would spend silent time in nature the day before the workshop, having worked a full week in the Downtown Eastside leading up to the sessions. I felt it was important to also be rested and sensitized, as facilitator. I tried to keep the facilitation and instructions to a minimum, while keeping a safe frame for the participants to experiment and explore. There was also a need for flexibility with the theme and to allow for talking and speech during the in between phases of the car ride or when transitioning again to indoor art making and ritual. Much of the guiding into silence was modelled in my behaviour and gentle reminders, as needed, when transitioning back into the studio space.

All workshops began at a multi-purpose meeting room at PHS Community Services Society. Our group would drive together to Stanley Park (a 400 hectare forested park in Vancouver, BC) and begin the work. The general structure always included:

1. Beginning in silence. We got out of the car, entered the park, and began on our trail silently.

2. Participants stood together, in silence, and attuned to the physical sensations of the environment.

3. We walked the trail together in silence for several minutes, and increased the duration of our silence each workshop.

4. We arrived at a pre-planned destination each time to initiate our walks and art-making in the forest.

5. Returned to the car in silence.

6. Return to the office for snacks, and combine elements from the walk 
into a new art making or ritual.

7. Participants would fill out a questionnaire and we would have an open discussion reflecting on questions and experiences.

Each workshop was individually designed, and participants were invited to join as many of the workshops as they were able. Participants, regardless of the number of sessions they attended, were given the opportunity to provide feedback on the impact that the sessions had on them.

A great deal of thought and effort went into the project design. The prospective attendees were highly stressed and time spent away from work was likely considered too precious to dedicate to activities that could be perceived as duties related to work. As the researcher was also a staff member, careful consideration was paid to the power relationships and privacy implications were important.

My research was completed under the supervision of the European Graduate School (EGS), which is an accredited University in Switzerland with EU accreditation in Malta. Two advisors and a senior faculty member reviewed and approved the project and consent process. The results were anonymized. Participants were again contacted prior to the submission to Art/Research International to confirm their consent to share materials, which they each granted.

\section{An Invitation}

The participants had each been invited by email to Expressive Arts Workshops in Stanley Park. The invitation was sent to over 500 PHS Society employees. A poster was included in the email that provided a brief description of the project and explained it as "an exploration of how expressive arts can help cultivate an embodied sense of silence and how that can nourish and support one through the stresses of daily life." It explained my interest in the ways we nourish ourselves and our communities with the arts and nature; and how silence can play a role in that healing process.

There were a total of three workshops held in the months of November and December, lasting four hours each. We worked within several contexts, including nature-based spaces and indoors at a PHS Community meeting room. Seven participants variously attended the workshop sessions.

This ritual of retreating to nature, to the arts, to silence, is what has helped me live and move through difficult times of working on the frontlines of the opioid crisis. As 
more and more of my co-workers took stress leaves, I wondered if there was something in my journey from anaesthesia to aesthetics that could be of benefit to others. The workshops were developed based on my own experiences with the work and I attempted to address curiosities and themes of silence and nature-based EXA practices.

\section{Results}

The following section includes the findings of the research. The workshops are presented thematically and include photographs of artwork and reflections of my coresearchers and my encounters with these themes throughout the research. The themes explored are: sensitizing through silence, aesthetics of silence, and poetic ecology through silence.

Participants' written responses are in italics, excerpts from discussions are prefaced by the speaker's initials, and I have also included poetry that I wrote using participants' aesthetic responses from art work in the workshops.

The first theme involved how participants were sensitized through silence. E. G. Levine writes, "sensitivity involves paying attention through all the senses, attuning to the potential for expression, sensing what possibilities there are for following the image and helping to shape it..." (2005, p. 253), and as Atkins states, each art modality calls us to be present with our senses and our own sense of aliveness (Eberhart et al., 2014, p. 78); as this research shows, so does silence.

The second theme involved considering the aesthetics of silence in exploration of what was the lived experience of silence. This section highlights how silence was articulated throughout the workshops and research. The artist who attempts to convey silence "must produce something dialectical: a full void, an enriching emptiness, a resonating or eloquent silence," (Sontag, 2002, p. 11). "Silence resounds with its own presence, adding meaning in ways that language alone can never accomplish" (Schroeder, 2016, p. 1).

The third theme looked at the emergence of a poetic ecology through silence. It highlights how participants reconnected with an eco-poetic sensibility in the context of nature-based expressive arts and how this helps inform, support and sustain us in our work on the frontlines. 


\section{Sensitizing Through Silence}

The Invitation: Wading Through Silence

I sent out an email invitation for the workshops in early November 2017 with a poster to the entire PHS staff pool.

I waited for expressed interest.

And I waited.

Several times, co-workers would approach me and explain that they were very interested, needed to find more time for self-care, but just didn't have the time now. And I waited.

No one signed up for the first workshop.

Participants would join and cancel at the last minute.

Panic.

A taste of the silence of not knowing.

A trip into Stanley Park in silence, on my bike.

\section{Silence}

This would become my pre-workshop ritual.

The second date for the workshops filled up.

It was cold.

Windy.

Rainy.

An extreme weather warning.

O.K.

Ready.

Workshop 1. Nervous laughter disappears into footsteps on a gravel path leading into Stanley Park.

"As we walk in silence together, begin to notice the sound of the rain on your hoods, the coolness of the water drops on your skin...." 
At first, being silent together felt strange. I was giggling inside. After less than a minute, I wondered what others were thinking... Then after that thought, I tuned in to what was around me, rather than in me, and felt super grounded and appreciative (M.E., 2017, workshop 1).

The details came into full view. Birds, colours, sounds. My mind stopped racing. I didn't think of my troubles or nagging thoughts... (B.S., 2017, workshop 1).

Workshop 2. They walked in silence to a place in the forest where there was space between trees and they gathered in a circle. They were invited to stretch and give the body any movement that it needed.

They were asked to close their eyes and listen as I read a poem, and prompted them to reflect on the following:

"Which question has been waiting for you and is asking for some attention? Now, take some time to journal with that question."

They free wrote in silence for 20 minutes.

I was more aware of what I was seeing and hearing - also feeling. I really digested my surroundings (M.H., 2017, workshop 2).

The focus became more introverted, despite also seeing more details about the path we were on too (L.K., 2017, workshop 2).

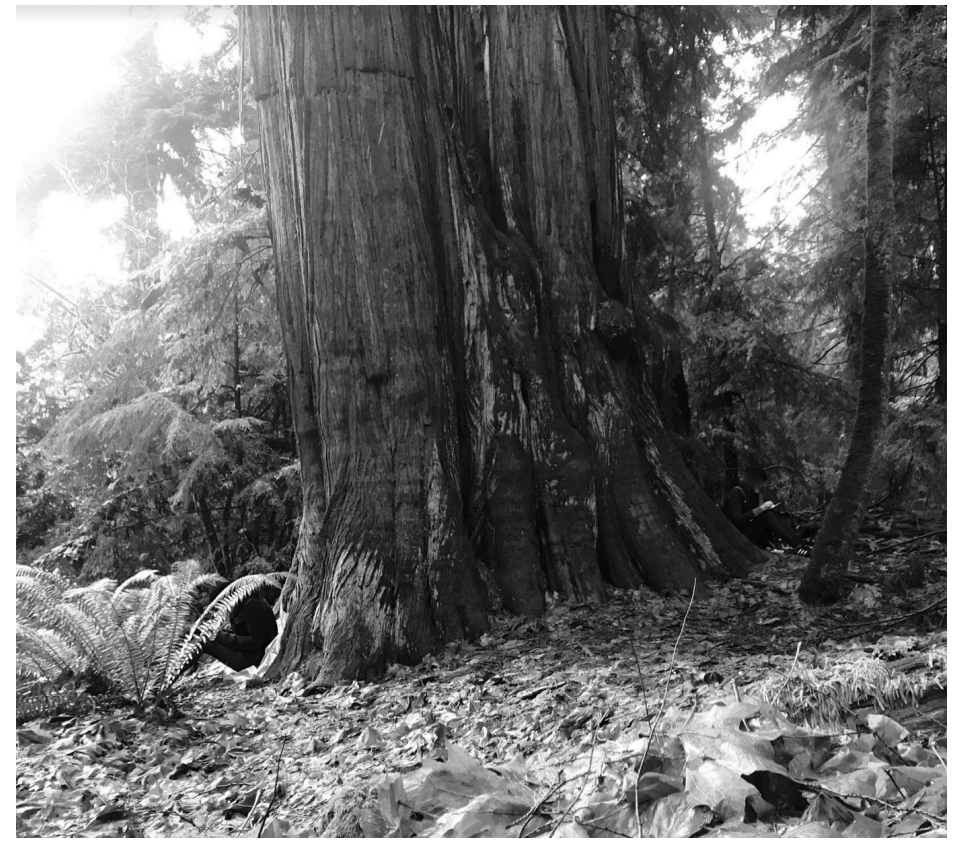

Figure 1

Workshop 3. Quietly plucking out used syringes from the mud in the community garden. Preparing the ground.

Two participants have not shown up. 
Ten minutes before the start time.

A text. They can't make it.

Another text: "Oh my god! I am so sorry! I totally forgot! I'll meet you at the park!"

An eagle screeches from the treetops above us. Ocean waves lapping in the distance.

CL: The ocean sounded perfect from there. You could barely hear these waves crashing. I noticed that right away. As soon as I got there I wanted to pick up on sounds and these things as soon as we started walking.

People, laughing, chatting. We get closer to the forest.

Voices turn into quiet murmurs.

The smells of the forest, the air, the trees, they bring up all kinds of emotions and memories for me. All these external things bring up new ideas and teachings (J.H., 2017, workshop 3).

\section{Aesthetics of Silence}

Workshop 1. Into the prehistoric forest they stride for duty and humanity, for peace, to heal.

They were unsure when the morning's music, the day's plans, the city's bits and pieces left their conscious minds, delegated to soft waves of memory....

The 5 are alone except for 3 dashing runners, one of whom dared to try and break the 5's vow of silence.

A man with an umbrella who passed understood. He offered only a gentle smile.

$\mathrm{He}$ is here in silence too (B.S., 2017, workshop 1).

They gathered materials from the forest piece by piece, in silence.

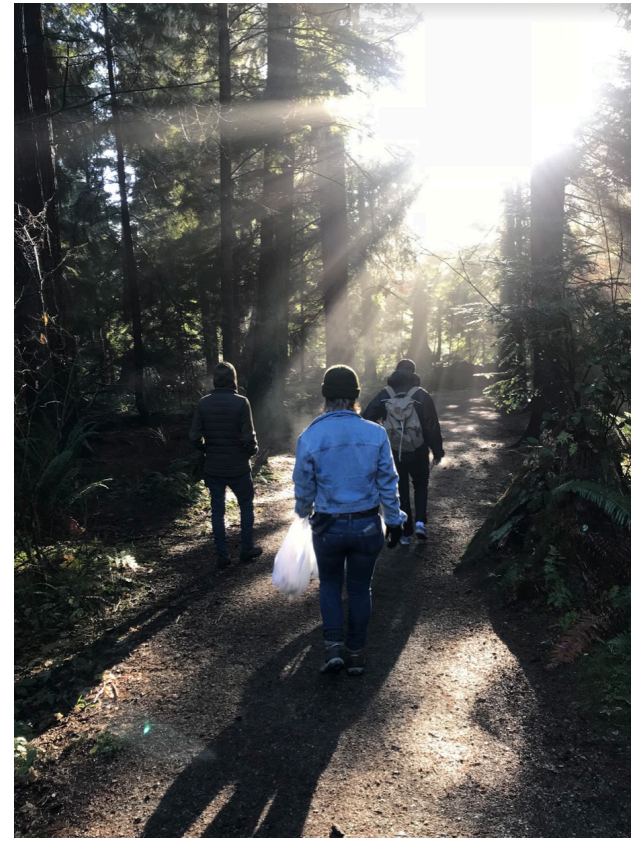

Figure 2 


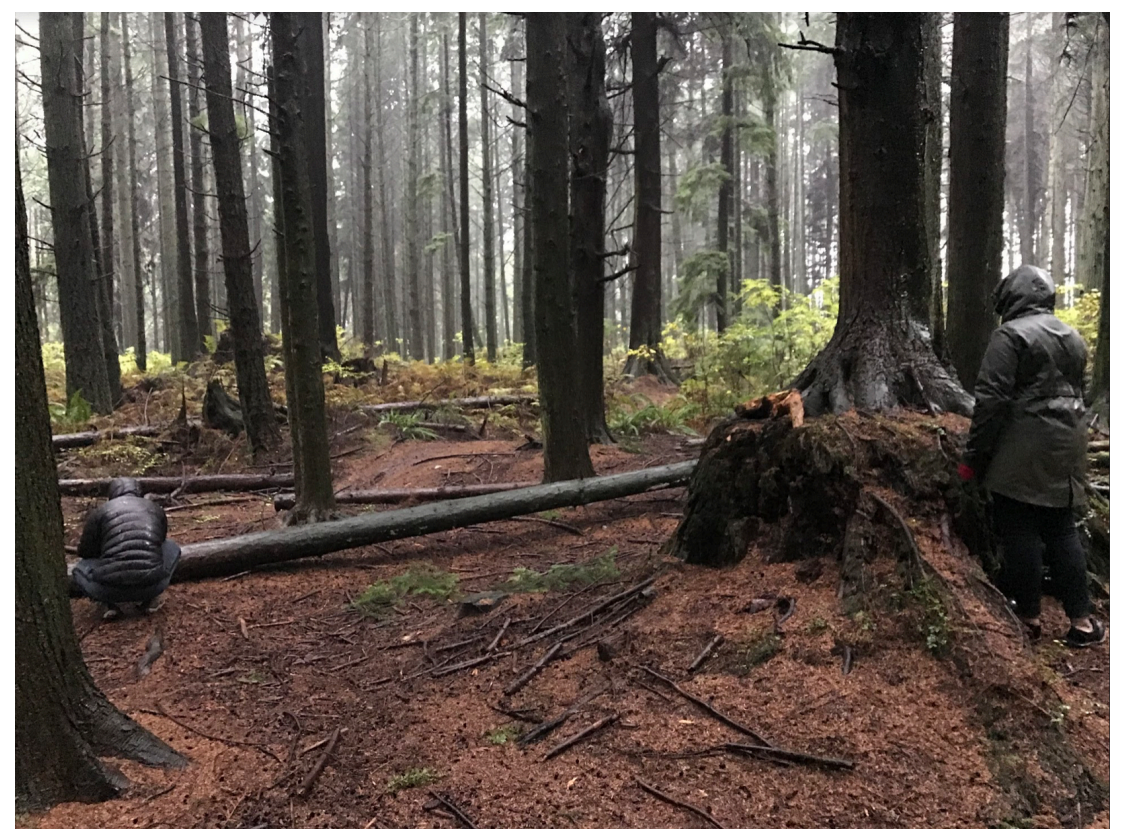

Figure 3

BM: Doing this job and having people talk to you about stuff you experience, the focus is always talk and talk about it but l've always been the type of person where I don't. I just sit and register it.

Coming to this and thinking about your mental health and all that kind of stuff but having people around you and just letting you be...

And I find that more comforting.

It's interesting not being forced to talk... You weren't forced to feel a certain way. You were just feeling what you were feeling because that's allowed.

Quieter than snow falling on a tree branch

Worries dissolve

Into cloudless smoke

Reaching fingertips

Pause for a repose

Edgeless edges blurred 


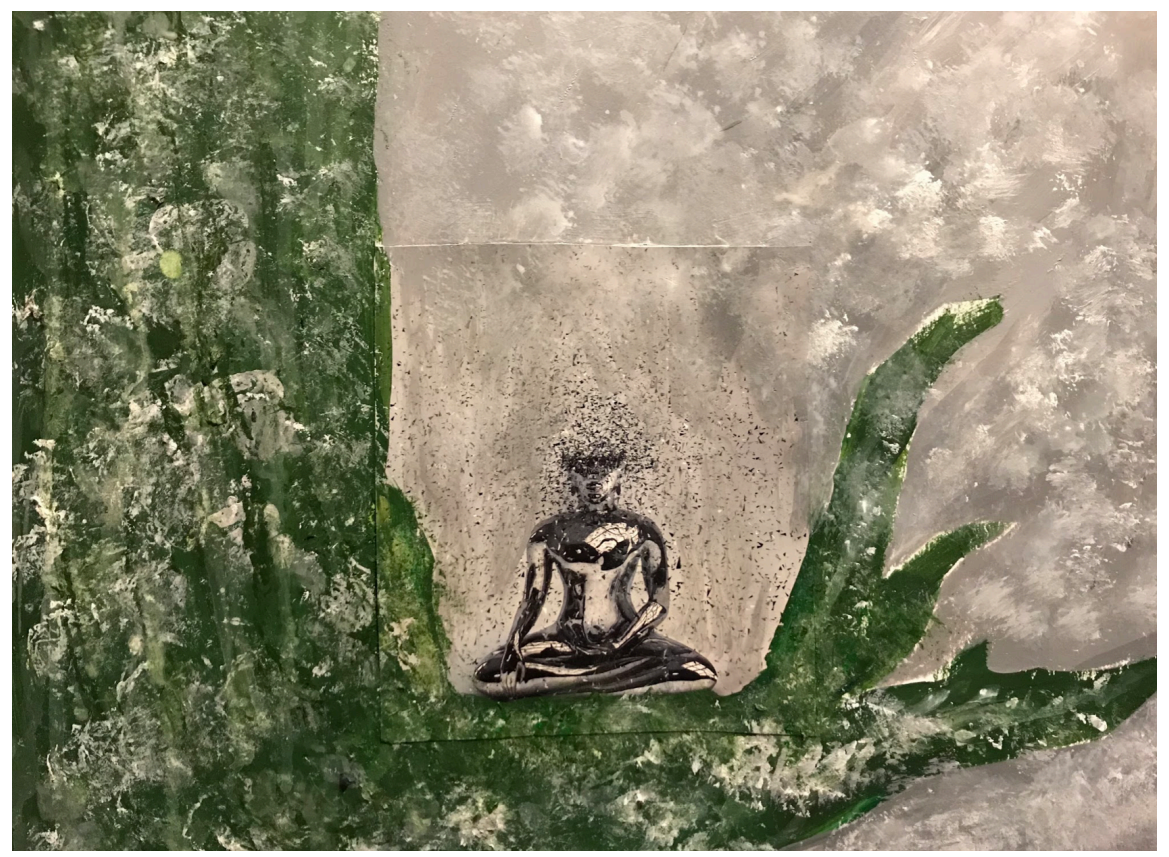

Figure 4

Workshop 2. Although there was no verbal communication it felt like there was a bond through presence (M.H., 2017, workshop 2).

LK: Being silent together made it validating but also that much more intentional. Rather than just being quiet because you were by yourself, being quiet intentionally in a group and just like the attention on that, being alone together basically.
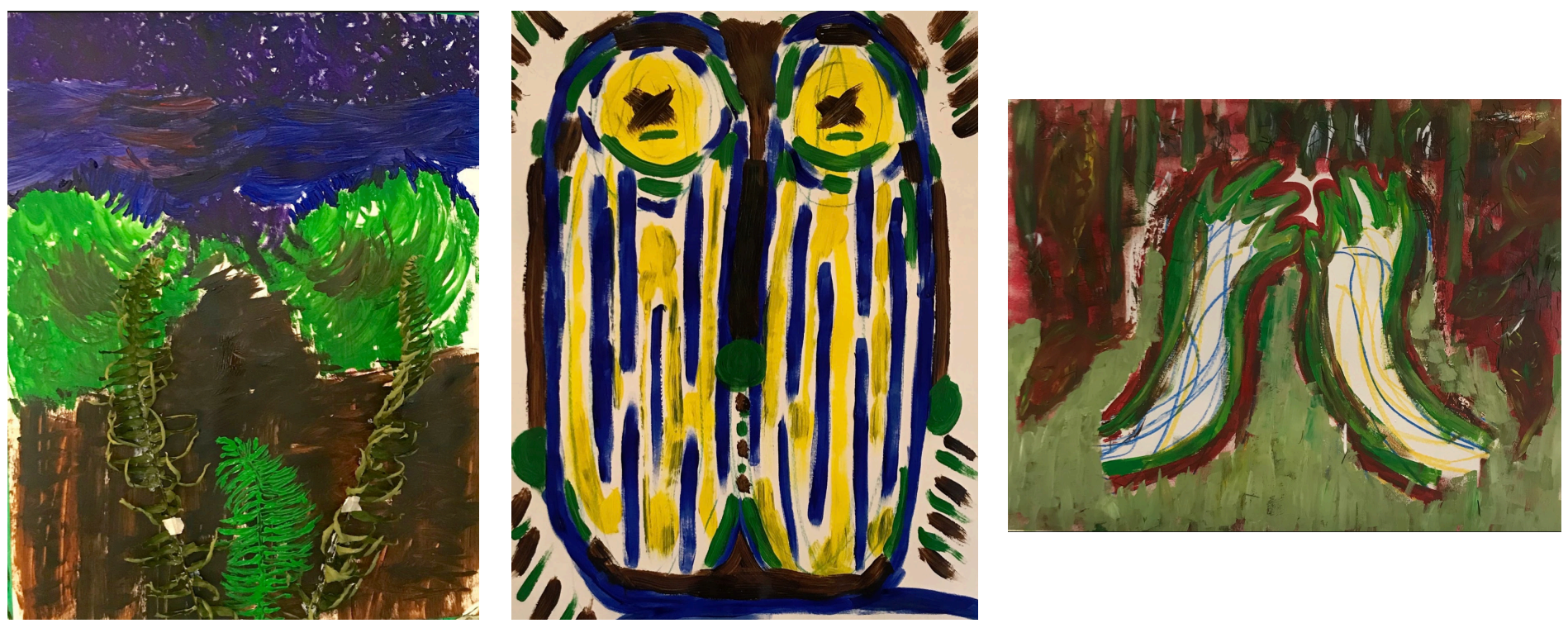

Figure 5, Figure 6, Figure 7 
Thanks for sharing

You left me speechless

Inside

Now outside

Some part of your branch

Ray of sunlight

Water droplet falling

Still moves inside me

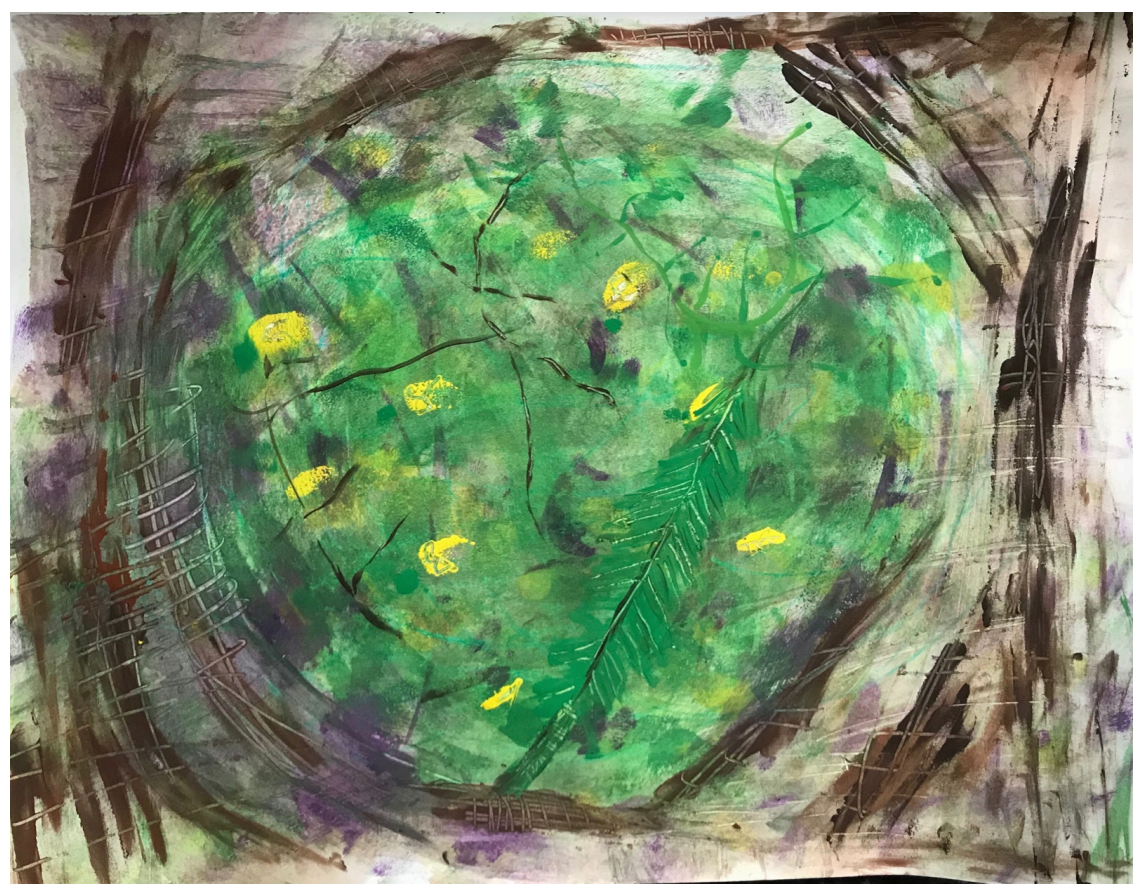

Figure 8

Workshop 3. JH: For me, as soon as we stopped talking you said something to do, as soon as we went silent I was like "no"

It completely changed.

It totally starting going in to relating to work.

I was like: "I don't want to carry anything home..."

Anything done outdoors in silence was more comfortable, where I don't feel like I'm doing a project beside someone else trying to do a "better project" (C.L., 2017, workshop 3). 


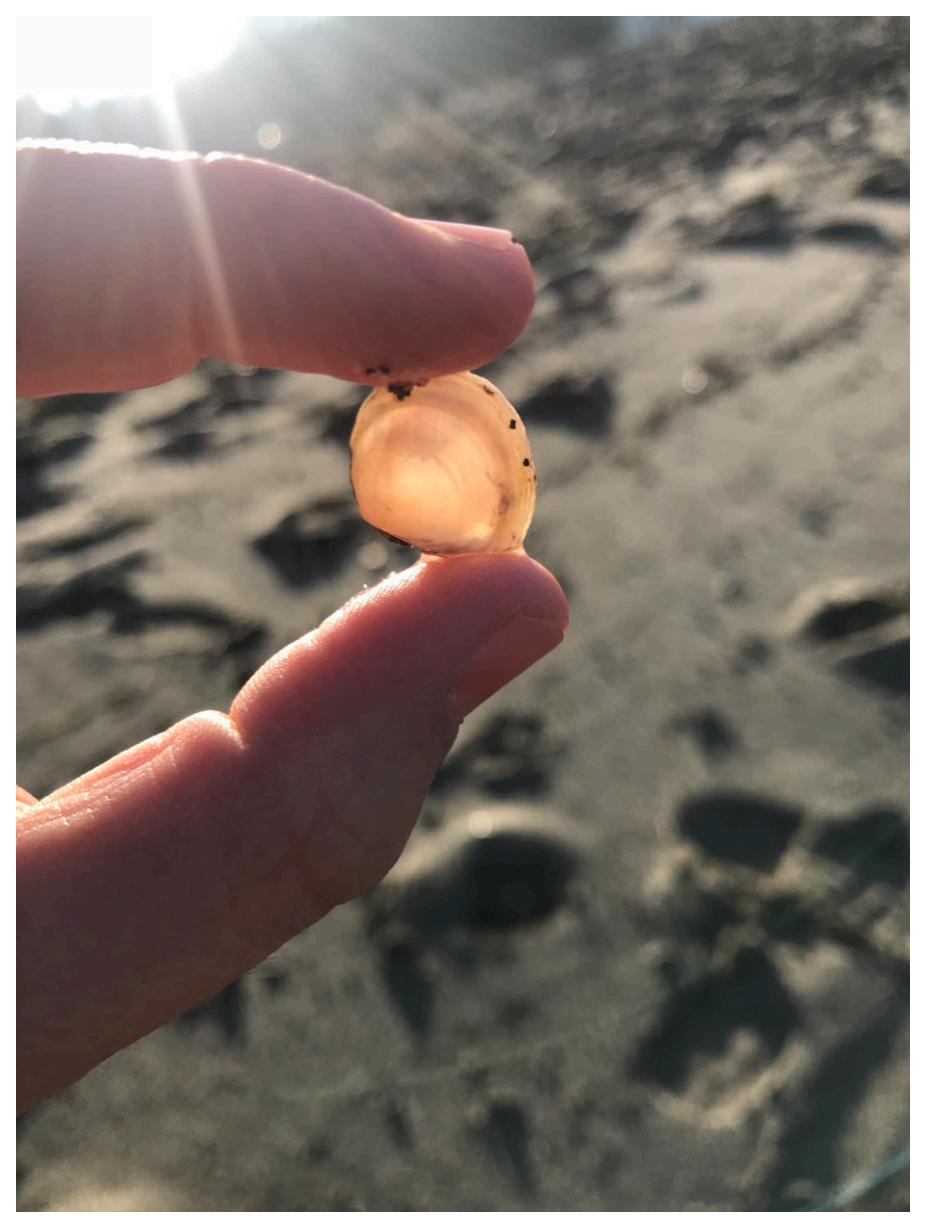

No art in response

Weight of talking

Weight of people

Weight on my bones

Waves washing up on the shore

A simple gesture

A wink

A nudge

A reminder

This too shall pass

Waves

Washing

Wearing down

Rocks and shells

To perfection

Shiny

Broken

And smooth

Delight in transparency

Figure 9

\section{A Poetic Ecology Through Silence}

Workshop 1. It was just a rock but it looked as though it had lost its purpose on the floor of that wood, so I brought it to my other findings and it belonged perfectly. Both death and life were represented in my arrangement of forest treasures. Kind of how the forest itself is a representation of both life and death, constantly being rinsed down by coastal showers (C.L., 2017, workshop 1).

When I lay down my random, non-green pieces it seemed to appear like a family under a roof. This was unintentional but made me appreciate my childhood and how lucky I am to share this wonderful experience and life (M.E., 2017, workshop 1). 


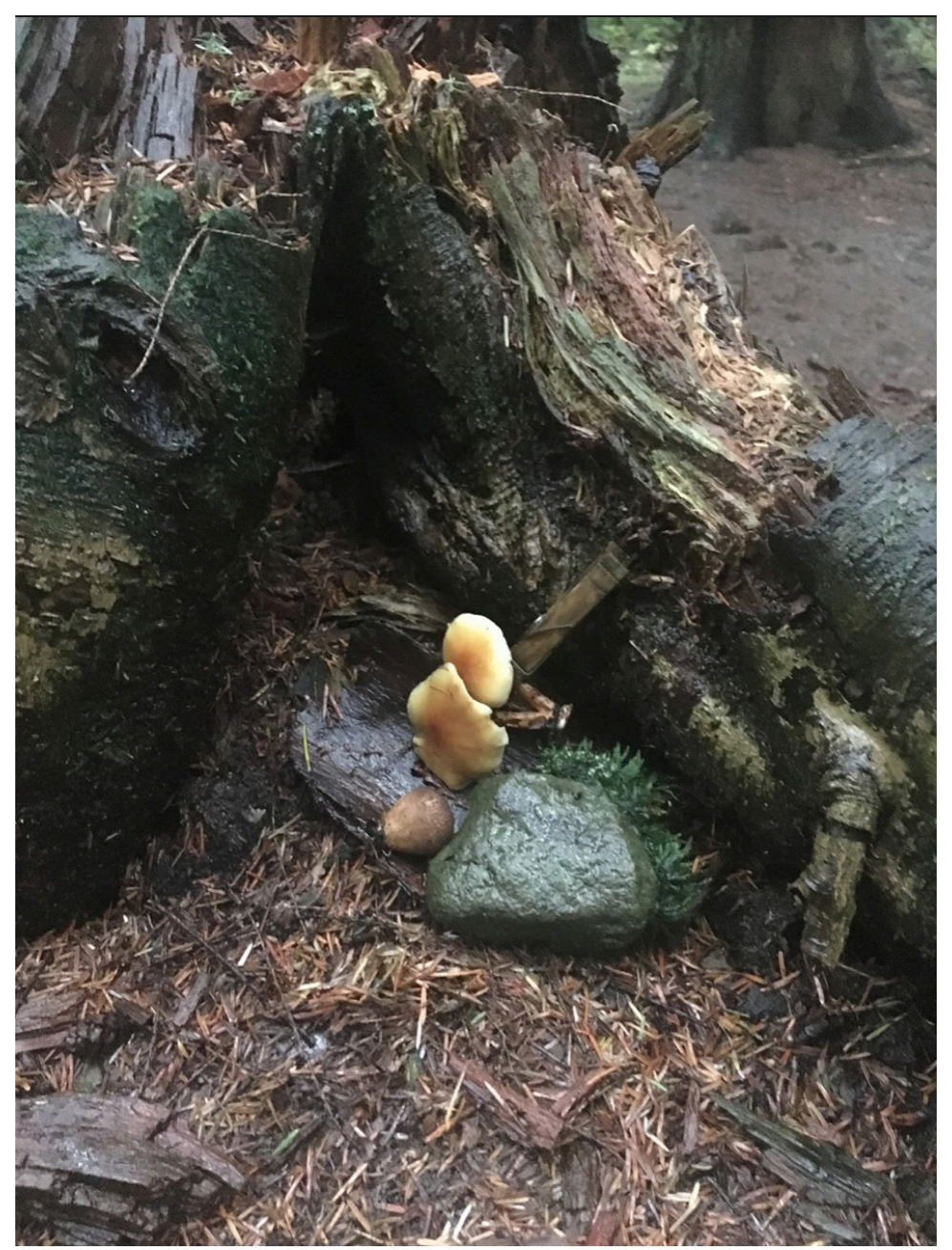

Figure 10

Workshop 2. CL: What is the question when the question doesn't matter in the end? You have this representation of this forest where it doesn't matter. You're alive enough to even have the question: will it be answered?

Cuz you're just going to return to the ground anyway.... You're going to be part of the cycle. 


\author{
GREEN PATHWAY \\ MISTY JOURNEY \\ FOG AND FUZZ \\ A WHISPY TRIUMPH
}

HOOT !

REACHING

HEALING HANDS

OF WARM TOUCH

\title{
SAD BEANS HOLDING HANDS \\ SISTERS \\ SYMMETRY \\ CLARITY
}

(Participants' aesthetic responses into poetry, 2018)

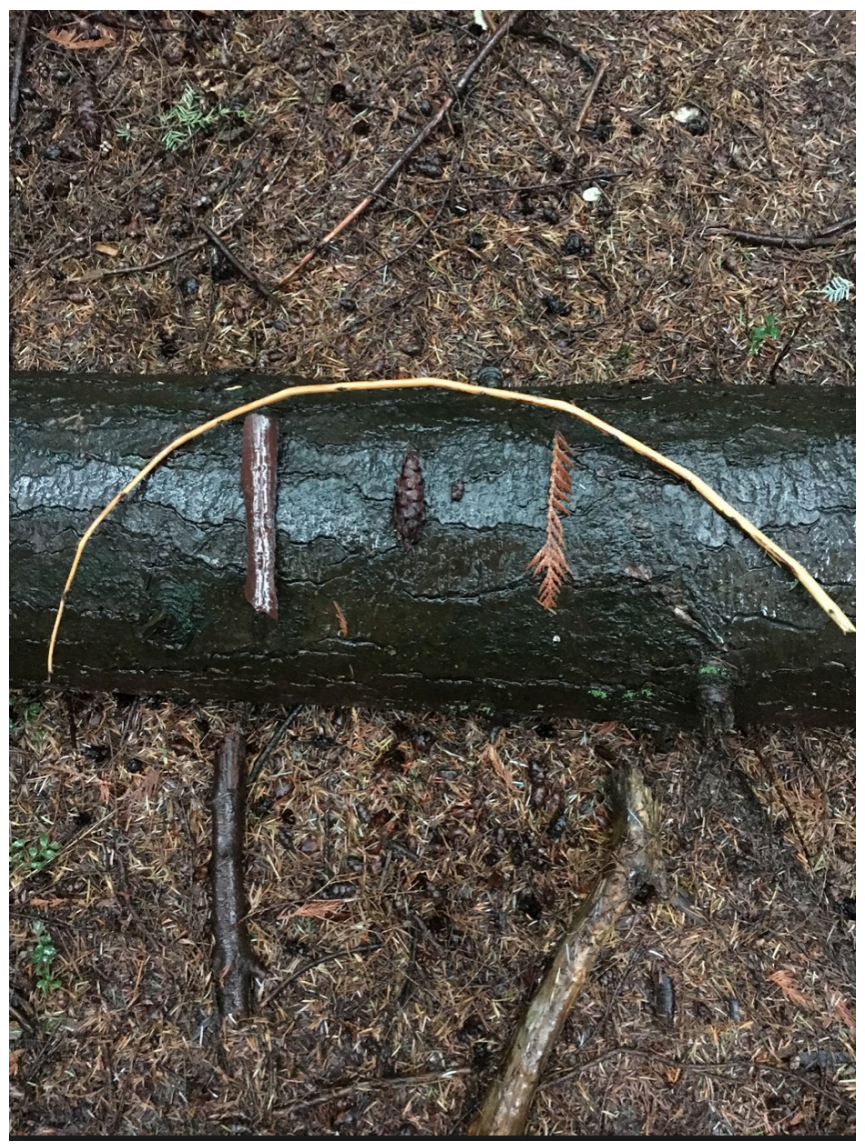

Figure 11 
Workshop 3. JH: Especially in the forest I was just seeing things that were rotting but there is still life coming out of them. They are still thriving but they are rotting and you can see they are rotting. There's a lot of people that are really suffering from addictions or poverty or disease or whatever but yet you talk to them and yet they are thriving.

ME: I picked up this other leaf shortly after... It had a lot of spikes on the sides and it reminded me of Val [name changed for confidentiality] and how high maintenance she is (laughs) and how all of those nicks mean something.

\author{
TIME \\ FOR OXYGEN \\ FOR GROWTH \\ TO BE SAFE \\ TO BREATHE FRESH \\ GRATITUDE IN THE STRENGTH OF UNDERSTANDING
}

(Participants' aesthetic responses into poetry, 2017)
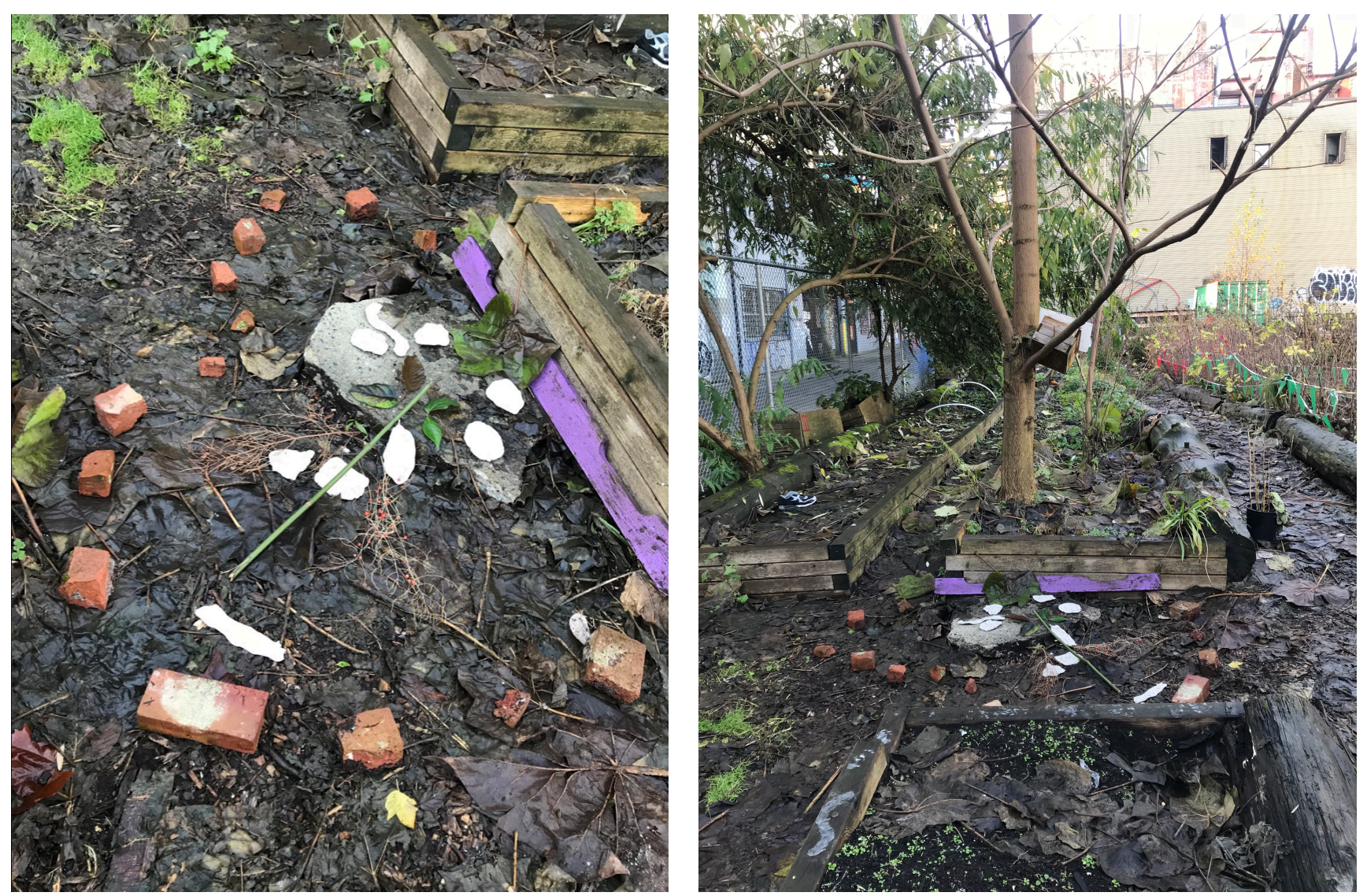

Figure 12, Figure 13 


\section{Alive Silence, Dead Silence}

Ambulance sirens are still a consistent element amidst the cacophony of sounds that you hear when walking along East Hastings in the Downtown Eastside. Overdoses are still a daily occurrence and frontline workers are still stressed and overworked. There are, however, little cracks and breaks in the seemingly rigid and constrictive conditions, which can offer space for new life to grow amidst so much death and loss.

This research started with a one-dimensional understanding of silence. Silence was seen as transcendental, gentle, and soothing. I soon discovered that if I were to give silence its due respect in this research, if I were to praise its complexities, then I would need to give voice to its more uncomfortable, sometimes heartbreaking thunderstorms. This was an important point in the research when I began to turn more fully towards silence. This embracing of the multiplicities of silence encouraged me to include the intricacies of the phenomenon and therefore help paint a fuller picture of the challenges facing my co-researchers and me, in my own work in the Downtown Eastside.

"Dead silence" deserves a voice. It is my hope that through this research, in my attempts to give space to both the alive and uncomfortable and anaesthetized and "burnt out" silences, I am staying true to the themes and questions at hand of creating more spaciousness and silence in this work in order to allow the poiesis of the work and the client to emerge more organically.

Per Espen Stoknes (2017) reminds us that our work in the arts encourages a greater sensitivity to the world and its usefulness in situations where we have forgotten our connection with the earth. By encouraging activists and those in power to engage with the arts, we can then loosen the grip that the habitual, instrumental and technological attitude has over the mind, and "let the body explore again the speech of things and of the land" (p. 260).

To get the understanding I got, I was surprised. And how nature directly reflects our society. Like how I was talking about how there are rotting trees that are down but yet they are thriving. And seeing how that relates to people who are suffering yet still thriving... (J.H., 2017, workshop 3).

In allowing silence to take shape in the practice of EXA, we give space for those "raw emotions" (M.H., 2017, workshop 2), as well as the more tender and gentle moments of intimacy. In working with Nature in silence we give space for her full range 
of expression of beauty and terror. We give space for the "terrorized person literally at a loss for words," as well as those moments of being rendered speechless in an "act of beauty," like a "beautiful thunderstorm" (Knill, 2006, p.114-115). We can challenge definitions and categorizations of burnout as a "distinct mental disorder" (Heinemann \& Heinemann, 2017, p.1-2), and move towards a sense of aliveness and connection with the life-world which we participate in and co-create.

Silence and Nature calibrate that internal compass that I, as an EXA therapist, sometimes neglect, telling it to come back another day. Silence and nature persist, reminding me to return to my animal body, to trust her instincts and impulses, her contractions and expansions and gentle and fierce whispers. When tired and confused, silence and Nature reorient me to the truth of the potent simplicity of the method of EXA therapy, and show me I can trust that.

\section{Forward Schemas}

Many of the participants and prospective participants with whom I spoke have struggled to carve out time for self-care and reported that they have found it difficult to schedule in a day or even a few hours just to focus on their wellbeing. There were initially four workshops proposed, however the first one had to be cancelled as no one registered. Interesting questions for further exploration would ask: What motivates one to do this high stakes, high intensity frontline work and what sustains those people that continue over the long term? How do organizations and agencies support their staff to engage this work long term, or is this even a priority? Those that did manage to find time to participate in Expressive Arts Workshops in Stanley Park reported that they found great benefit. One participant shared with the author an Instagram post they made: "Today I made art. Not good art but healthy art. There is power in silence..." (M.H., 2017, workshop 2).

A discovery in this research was the richness of the discussions that followed the EXA experiments in silence. To my surprise, the discussions at the end of each session went well beyond the planned fifteen minutes and many of the participants were eager to speak up and give voice to their shared experience. One participant's comment makes me curious around what would happen if there was more freedom to bring in the use of voice:

I think the other thing about being silent in a group is you know when you are alone and those emotions and feelings come up, you're alone and you just have to be with them. And then you are like, "Ok," and try to remember this and 
understand it. But when you are with other people, you are like ok "hey I just understood, I just got something ..." when you are in a group you are like "oh I can't say it" (J.H., 2017, workshop 3).

What can silence give voice to?

As someone who has worked on the frontlines in the Downtown Eastside since 2011, it has been my experience that there is a silence between frontline professionals such as paramedics, firefighters, and other emergency first responders and me and my colleagues at the PHS Community Services Society. I am very curious how expressive arts and silence could potentially provide a platform for cross-disciplinary dialogue while fostering greater cooperation and understanding of the challenges and strengths we possess as unique professions and as a collective that serves the same community.

In times when chaos is the everyday experience on the frontlines of the opioid epidemic in the Downtown Eastside, as well as many communities across North America, opportunities to move through a chaotic space of uncertainty, the intentional ritual of the EXA art making experience can provide an opportunity to give voice to and create coherence of seemingly bleak uncertainty. In doing so, as a collective, we, in the words of Vikki Reynolds (2013), "shoulder each other up" in solidarity (p. 56).

It is my strong belief and experience that these moments of adversity and unimaginable loss - when given a voice as a collective, have the power to alchemize atrocity into gold. This "liminal condition" (van Gennep, 1960, cited in S. K. Levine, 2005 , p. 42-43), one in which all familiar structures have given way, in a time in which the new has yet to come into being, has a potent message that begs for creative alternatives to a system that is fundamentally forgetting and failing the people that need it most. Expressive arts and silence, I believe, can be a powerful catalyst to help give shape and voice to support this much needed paradigm shift. 


\section{Acknowledgements}

I would like to thank Richard Wainwright and Roberta Rasmussen-Merz for their generous support and warm guidance throughout this research journey. I would also like to thank my co-researchers. This work would not have been possible without them. 


\section{REFERENCES}

Atkins, S. S., \& Snyder, M. A. (2017). Nature-based expressive arts therapy: Integrating the expressive arts and ecotherapy. London, UK: Jessica Kingsley.

Barone, T., \& Eisner, E. (2012). Arts based research. Thousand Oaks, CA: Sage.

Berry, T. (1988). The dream of the earth. San Francisco, CA: Sierra Club Books.

Brend, Y. (2016, June 9) Overdose crisis is 'our Ebola', says Dr. Mark Tyndall. CBC News. Retrieved from: http://www.cbc.ca/news/canada/british-columbia/ overdose-deaths-fentanyl-w-18- centre-for-excellence-mark-tyndall-1.3624318

Campbell, L., Boyd, N., \& Culbert, L. (2009). A thousand dreams: Vancouver's Downtown Eastside and the fight for its future. Vancouver, BC: Greystone Books.

Cage, J. (1961). Silence: Lectures and writings. Middletown, CT: Wesleyan University Press.

Central City Foundation. (2017). On the frontlines of the opioid crisis: How community organizations and their staff are coping. Retrieved from:

https://www.centralcityfoundation.ca/wp-content/uploads/2017/12/CCFCommunityReport-2017_F3web.pdf

City of Vancouver. (2015). Annual procurement report. Retrieved from: http://vancouver.ca/files/cov/annual-procurement-report-2015.pdf

Coroner's Service of BC. (2019, May 15). Illicit drug overdose deaths in BC January 1, 2009 - March, 2019. Retrieved from: https://www2.gov.bc.ca/assets/gov/birthadoption-death-marriage-and-divorce/deaths/coroners-service/statistical/illicitdrug.pdf

Deleuze, G. (1988). Foucault. Minneapolis, MN: University of Minnesota Press. Retrieved from: https://altexploit.files.wordpress.com/2017/05/gilles-deleuzesean-hand-foucault-university-of-minnesota-press-1988.pdf 
Eberhart, H., Atkins, S. \& Knill, P. (2014). Presence and process in expressive arts work: At the edge of wonder. London, UK: Jessica Kingsley.

Espen Stoknes, P. (2015). What we think about when we try not to think about global warming: Toward a new psychology of global warming. White River Junction, VT: Chelsea Green Publishing.

Espen Stoknes, P. (2017). Why ecophilosophy and expressive arts? In S.K. Levine, \& E. G. Levine, (Eds.), New developments in expressive arts therapy: The play of poeisis. (pp. 258-260). London, UK: Jessica Kingsley Publishers.

Havens, L. (1979). Explorations in the uses of language in psychotherapy: Complex empathic statements. Psychiatry: Journal for the Study of Interpersonal Processes, 42(1), 40-48.

Heinemann, L. V., Heinemann, T. (2017). Burnout research: emergence and scientific investigation of a contested diagnosis. Sage Open, 7(1), 1-12. https://doi.org/10.1177/2158244017697154

Hernandez, P., Gangsei, D. \& Engstrom, D. (2007). Vicarious resilience: A new concept in work with those who survive trauma. Family Process, 46(2), 229-241.

Herman, J. L. (1992). Trauma and recovery. New York, NY: Basic Books.

Kellen-Taylor, M. (1998). Imagination and the world: a call for ecological expressive therapies. The Arts in Psychotherapy, 25(5), 303-311. https//:doi.org/10.1016/s0197-4556(98)00048-3

Kenny, G. (2012). An introduction to Moustakas's heuristic method. Nurse Researcher, 19(3), 6-11. https//:doi.org/10.7748/nr2012.04.19.3.6.c9052

Knill, P. J. (2005). Foundations for theory and practice. In P. J. Knill, E. G.Levine, \& S. K. Levine (Eds.), Principles and practice of expressive arts therapy: Toward a therapeutic aesthetics, (pp. 75-169). London, UK: Jessica Kingsley Publishers.

Knill, P. J. (2006). Can terror be beautified? Poiesis: A Journal of the Arts and Communication, 8, 114-117.

Knill, P. J., Barba, H., \& Fuchs, M. (2003). Minstrels of soul: Intermodal 
expressive arts therapy. Toronto, ON: EGS Press.

Levine, E. G. (2005). The practice of expressive arts therapy: Training, therapy and supervision. In P. J. Knill, E. G. Levine, \& S. K. Levine (Eds.), Principles and practice of expressive arts therapy: Toward a therapeutic aesthetics. (pp. 171255). London, UK: Jessica Kingsley Publishers.

Levine, P. (2010). In an unspoken voice: How the body releases trauma and restores goodness. Berkeley, CA: North Atlantic Books.

Levine, S. K. (2005). The philosophy of expressive arts therapy: Poeisis as a response to the world. In P. J. Knill, E. G. Levine, \& S. K. Levine (Eds.), Principles and practice of expressive arts therapy: Toward a therapeutic aesthetics. (pp. 15-73). London, UK: Jessica Kingsley Publishers.

Levine, S. K. (2012). Nature as a work of art: Towards a poetic ecology. Poiesis: $A$ Journal of the Arts and Communication, 14, 186-193.

Levine, S. K. (2015). The Tao of poiesis: Expressive arts therapy and Taoist philosophy. Creative Arts in Education and Therapy, 1(1), 15-25. https//:doi.org/10.15534/ caet/2015/1/4

Lupick, T. (2017). Fighting for space: How a group of drug users transformed one city's struggle with addiction. Vancouver, BC: Arsenal Pulp.

Moustakas, C.E. (1990). Heuristic research: Design, methodology and applications. Newbury Park, CA: Sage Publications.

Naess, A. (1973). The shallow and the deep, long-range ecology movement: A summary. Inquiry: An Interdisciplinary Journal of Philosophy and the Social Sciences, 16, 95-100. https://doi.org/10.1080/00201747308601682

Naess, A. (1995). Self-realization: An ecological approach to being in the world. In G. Sessions (Ed.), Deep ecology for the twenty-first century, (pp. 225-239). Boston, MA: Shambala Publications.

Nelson, M. P. (2008) Deep ecology. Encyclopedia of Environmental Ethics and 
Philosophy, 18(8), 206-221. Retrieved from:

http://www.uky.edu/OtherOrgs/AppalFor/Readings/240\%20-\%20Reading\%20\%20Deep\%20Ecology.pdf

Reynolds, V. (2013). "Leaning in" as imperfect allies in community work. Narrative and Conflict: Explorations in Theory and Practice, 1(1), pp. 53-75. https://doi.org/10.13021/G8ncetp.v1.1.2013.430

Reynolds, V. (2011). Resisting burnout with justice doing. The International Journal of Narrative Therapy and Community Work, (4), pp. 27-45. Retrieved from: https://vikkireynoldsdotca.files.wordpress.com/2017/12/ reynolds2011resistingburnoutwithjustice-doingdulwich.pdf

Seccia, S. (2017). We're Losing what our SRO's can do right. The Tyee. Retrieved from: https://thetyee.ca/News/2017/02/13/Losing-What-SROs-Do-Right/

Schroeder, B. (2016). Spectacular silence: reflections on nihilism, violence and awakening. Four By Three Magazine. Retrieved from: http://www.fourbythreemagazine.com/issue/silence/spectacular-silence

Sontag, S. (2002). Styles of radical will. London, UK: Penguin Books.

van Gennep, A. (1960). The rites of passage. Chicago, IL: The University of Chicago Press. 